\title{
Heat Treatment of Cold-Sprayed C355 Al for Repair: Microstructure and Mechanical Properties
}

\author{
J. W. Murray $^{1}$ M. V. Zuccoli ${ }^{1}$ T. Hussain ${ }^{1}$
}

Submitted: 17 July 2017 /in revised form: 13 November 2017/Published online: 22 November 2017

(c) The Author(s) 2017. This article is an open access publication

\begin{abstract}
Cold gas dynamic spraying of commercially pure aluminum is widely used for dimensional repair in the aerospace sector as it is capable of producing oxide-free deposits of hundreds of micrometer thickness with strong bonding to the substrate, based on adhesive pull-off tests, and often with enhanced hardness compared to the powder prior to spraying. There is significant interest in extending this application to structural, load-bearing repairs. Particularly, in the case of high-strength aluminum alloys, cold spray deposits can exhibit high levels of porosity and microcracks, leading to mechanical properties that are inadequate for most load-bearing applications. Here, heat treatment was investigated as a potential means of improving the properties of cold-sprayed coatings from $\mathrm{Al}$ alloy C355. Coatings produced with process conditions of $500{ }^{\circ} \mathrm{C}$ and 60 bar were heat-treated at $175,200,225$, $250{ }^{\circ} \mathrm{C}$ for $4 \mathrm{~h}$ in air, and the evolution of the microstructure and microhardness was analyzed. Heat treatment at 225 and $250{ }^{\circ} \mathrm{C}$ revealed a decreased porosity ( $\sim 0.14 \%$ and $0.02 \%$, respectively) with the former yielding slightly reduced hardness (105 versus $130 \mathrm{HV}_{0.05}$ as-sprayed). Compressive residual stress levels were approximately halved at all depths into the coating after heat treatment, and tensile testing showed an improvement in ductility.
\end{abstract}

This article is an invited paper selected from presentations at the 2017 International Thermal Spray Conference, held June 7-9, 2017, in Düsseldorf, Germany, that has been expanded from the original presentation.

T. Hussain

tanvir.hussain@nottingham.ac.uk

1 Faculty of Engineering, University of Nottingham, Nottingham NG7 2RD, UK
Keywords aluminum alloys $\cdot$ cold spray $\cdot$ heat treatment $\cdot$ repair · solution heat treatment

\section{Introduction}

Cold spraying (CS) is a materials deposition process in which particles of diameter typically between 5 and $45 \mu \mathrm{m}$, but as large as $100 \mu \mathrm{m}(\operatorname{Ref} 1)$, are accelerated in the solid state to high velocities $(300-1200 \mathrm{~m} / \mathrm{s}$ ) and develop a deposit by an impaction process (Ref 2). Since the mechanism of adherence of particles to the substrate relies on their plastic deformation, cold spraying of hard materials such as ceramics is difficult, whereas spraying of softer materials, such as $\mathrm{Al}(\operatorname{Ref} 3), \mathrm{Cu}(\operatorname{Ref} 4)$ and $\mathrm{Ti}(\operatorname{Ref} 5)$, is effective and widely used. CS can produce thick deposits, of several hundred micrometer thickness. Given the submelting point temperatures used in CS, deposits avoid the deleterious effects of equivalent high-temperature thermal spraying processes, including oxidation, recrystallization, and amorphization. CS is a particularly promising technology for the repair of light alloys for the aerospace industry, including aluminum, magnesium and titanium alloys, which have undergone wear and corrosion (Ref 6). The process can offer strong financial advantages given the ability to repair as opposed to having to replace the part. Currently, commercially pure Al deposits sprayed by CS are typically characterized by acceptable ultimate tensile strength and Young's modulus in uniaxial tensile tests, but nearly no ductility (Ref 7). Furthermore, the presence of porosity and other deposition defects can adversely affect mechanical properties of the repairs (Ref 6). Also, residual stresses arising from CS can lead to interfacial adhesive failure of the deposits (Ref 8,9). The limitations of porosity and poor interfacial adhesion prevent CS 
technology from being applied to structural repair of $\mathrm{Al}$ alloy components.

Heat treatment of cold-sprayed deposits to improve mechanical properties has been widely used in the past for $\mathrm{Cu}, \mathrm{Al}, \mathrm{Ti}, \mathrm{Ni}$, and many other deposits (Ref 10). Coalescence of porosity in the deposited coating was observed with heat treatment, including the healing of poorly bonded interfaces between deposits via solid state diffusion. In addition, the hardness of the deposit decreased with both heat treatment temperature and time. Post-deposition heat treatment of cold-sprayed deposits is a suitable route to improve mechanical properties. Some studies exist on heat treatment of pure aluminum (Ref 7), but less research has been done on cold-sprayed Al alloys. Rokni et al. have heat-treated cold-sprayed 7075 (Ref 11) Al alloy. Mechanical properties were enhanced by both low- and high-temperature heat treatment. Ductility and strength increased after low-temperature heat treatment $\left(121^{\circ} \mathrm{C}\right.$ for $24 \mathrm{~h}$ ), explained by precipitate formation. At higher temperatures, atomic diffusion and microstructural sintering also enhanced bonding between deposited particles, in turn improving mechanical properties. Rokni et al. (Ref 12) showed a similar trend in the case of heat treatment of 6061 cold-sprayed Al alloy. Here, ductility and UTS showed a slight increase with heat treatment, attributed again to improved metallurgical bonding at prior particle boundaries as well as a modest increase in precipitate density. Hall et al. (Ref 13) performed heat treatment in air on coldsprayed commercially pure aluminum, using $300{ }^{\circ} \mathrm{C}$ temperature and $22 \mathrm{~h}$ annealing parameters. This yielded a significant increase in ductility ( $10 \%$ elongation compared to $<1 \%$ ); however, ultimate strength was reduced. This change in properties was explained by grain growth and/or a reduction in dislocation density. However, this behavior has not been investigated in the case of more complex $\mathrm{Al}$ alloys with other minor alloying elements.

Residual stress present in sprayed coatings is a complex phenomenon which strongly influences final coating properties and has been studied widely (Ref 14-16). It is known that residual stress type and value depends strongly on sprayed material type, as well as substrate type and method of surface preparation (Ref 17). For example, residual stress for cold-sprayed commercially pure aluminum showed consistently, but to varying extents, tensile residual stress, whereas sprayed pure $\mathrm{Ti}$ and pure $\mathrm{Cu}$ coatings tended to be compressive in nature. Other work also observed a compressive coating residual stress which varied with standoff distance for zinc coatings sprayed on mild steel (Ref 18). Critically, the relationship between residual stress and depth from the top surface of the coating has not been studied for heat-treated cold-sprayed deposits.

Although the near pure Al alloys have been well characterized regarding both their cold spray and heat treatment properties, high silicon Al alloys are not as well understood, particularly regarding the heat treatment of their cold-sprayed coatings. C355 Al alloy ( $\mathrm{Si} 4.5-5.5 \%, \mathrm{Cu}$ $1-1.5 \%, \mathrm{Mg} \mathrm{0.4-0.6 \% )}$ is an example of a high silicon $\mathrm{Al}$ alloy and was chosen in this study since it is a quaternary alloy (Al-Si-Cu-Mg) which is widely used for structural aerospace applications (Ref 19).

In this work, post-deposition heat treatment of coldsprayed C355 Al alloy coatings was performed to improve the microstructure and mechanical properties of the assprayed coatings.

\section{Experimental}

\section{Cold Spray and Heat Treatment}

Gas-atomized C355 Al alloy powder with a size range of $-65+45 \mu \mathrm{m}$ was sourced from LPW Technology, UK. Coatings were sprayed using a high-pressure cold spray system (Impact 5/11, Impact Innovations $\mathrm{GmbH}$, Germany) equipped with a water-cooled nozzle and nitrogen as a process gas. A range of process gas temperatures (350$500{ }^{\circ} \mathrm{C}$ ), pressures $(40,50$ and 60 bar), and standoff distances (SOD) (20-50 mm) were initially investigated. Powder feed rate at $3 \mathrm{rpm}$, yielding a rate of 10-15 g/min, with a $1 \mathrm{~mm}$ track spacing and $100 \mathrm{~mm} / \mathrm{s}$ traverse speed was used in all spray trials. Aluminum alloy 6082-T6 (Si $0.7-1.3 \%, \mathrm{Mg}$ 0.6-1.2\%, Mn 0.4-1.0\%, Al bal) substrate grit blasted with 120-grit was used. A total deposition thickness of $\sim 400 \mu \mathrm{m}$ was produced with two passes of the spray gun.

Post-deposition heat treatment at a range of temperatures $\left(175,200,225,250^{\circ} \mathrm{C}\right)$ was carried out on the coating which showed the least porosity. Primary gas temperature was $500{ }^{\circ} \mathrm{C}$, gas pressure was 60 bar, and standoff distance was $50 \mathrm{~mm}$. The dwell time was $4 \mathrm{~h}$ for all heat treatments which was chosen based on minimum heat treatment time required for bulk C355 alloy, based on heat treater's guide (Ref 20). All heat treatments were performed in air using preheated furnaces. After $4 \mathrm{~h}$, the samples were removed from the furnaces and left to cool in air at room temperature.

\section{Microstructural Analysis}

All samples were sectioned, hot mounted, ground, and polished to a $1-\mu \mathrm{m}$ diamond finish, followed by $0.06-\mu \mathrm{m}$ colloidal silica finish. Hot mounting temperature was approximately $150{ }^{\circ} \mathrm{C}$ and was performed for $10 \mathrm{~min}$, and therefore was not considered to have a notable influence on microstructure. Powders were also cold mounted and polished the same way. Samples were etched using modified 
Keller's reagent $(2 \mathrm{ml} \mathrm{HF}, 3 \mathrm{ml} \mathrm{HCl}, 20 \mathrm{ml} \mathrm{HNO}$, $175 \mathrm{ml}$ water). Microstructural analysis was conducted via optical microscopy (OM) (Eclipse LV100ND, Nikon, Japan), scanning electron microscopy (SEM) (JEOL JSM 64900LV, Japan), electron probe microanalysis (EPMASuperprobe JEOL JXA 8200, Japan), and x-ray diffractometry (XRD-D500 Diffractometer, Siemens, Germany). Image analysis for porosity estimation was performed using ImageJ software (National Institutes of Health, USA). Ten $300 \times 240 \mu \mathrm{m}$ images were used to calculate the average level of porosity and standard deviation. SEM at $20 \mathrm{kV}$ was used to perform energy-dispersive $\mathrm{x}$-ray spectroscopy (EDS) for phase identification. A superprobe operating at $30 \mathrm{kV}$ was used for high-resolution elemental mapping via wavelength-dispersive spectroscopy (WDS). XRD scans were run using $\mathrm{Cu}-K \alpha$ radiation with $0.154 \mathrm{~nm}$ wavelength in the $2 \theta$ range of $18^{\circ}-120^{\circ}$, with a $0.02^{\circ}$ step size and $10 \mathrm{~s}$ per step. X'Pert HighScore with access to the PDF- 2 database was used for phase identification. Rietveld refinement (Ref 21) was performed in TOPAS V5 software (Coelho Software, Australia) for quantitative phase composition and lattice parameter refinement. Finally, Whole Powder Pattern Modelling (WPPM) (Ref 22) was used to determine the average sizes of coherently scattering domains (CDD) and microstrains. Instrumental broadening was accounted for by using the socalled fundamental parameters approach, using known instrumental parameters (Ref 22). The relation $\rho=2 \sqrt{ } 3 \varepsilon \mathrm{d}^{-1} \mathrm{~b}^{-1}$ was used to calculate dislocation density $\rho\left(\mathrm{m}^{-2}\right)$, where $\varepsilon(\%)$ is the value of microstrain, $\mathrm{d}$ is the grain size (estimated using the measured CDD) [nm], and $b=0.286 \mathrm{~nm}$ is the magnitude of the Burgers vector for an FCC Al alloy (Ref 23). This relation is commonly used when studying aluminum alloys subject to severe plastic deformation, and hence can sensibly be used here to estimate the dislocation density in both the as-sprayed and heat-treated deposits.

\section{Mechanical Characterization}

Microhardness measurement was performed using a Vickers microhardness tester (MMT-7, Buehler, Illinois, USA) equipped with a standard diamond pyramid indenter. A 50-gf load was used for all CS coatings, and $10 \mathrm{gf}$ for powders. For each sample, 15 measurements were taken, with spacing according to ASTM standard (E384-16). Nanohardness measurement was performed using a $10-\mathrm{mN}$ load. A total of 25 and 100 measurements were performed for powders and coatings, respectively. The measured nanohardness in GPa has been converted into Vickers hardness number for comparison with microhardness results.
Microflat tensile (MFT) testing (see e.g., Ref 24) was performed at room temperature using a tensile testing system (Instron 5969, Instron, Buckinghamshire, UK) with a crosshead speed of $0.5 \mathrm{~mm} / \mathrm{min}$. Elongation was measured with a non-contacting extensometer. MFT specimens were obtained from 0.4-mm-thick free-standing coatings and cut using precision computer numerical control (CNC) machine. Sample geometry and dimensions $(10 \mathrm{~mm}$ gauge length, $3 \mathrm{~mm}$ gauge width, 0.4 thickness) were chosen according to ASTM E8/E8M-16a and other work (Ref 25). The yield strength was determined using the $0.2 \%$ offset method. The first-order residual stress profile was measured using a portable x-ray diffractometer (AST X-Stress 3000, American Stress Technologies Inc., Pennsylvania, USA) emitting $\mathrm{Cr}-\mathrm{K} \alpha$ radiation at $30 \mathrm{kV}$ and $6.5 \mathrm{~mA}$. Measurements were taken with diffraction angle $2 \theta$ calibrated at $139.3^{\circ}$ for $\mathrm{Al}$, irradiating an area of $4 \mathrm{~mm}$ diameter. A total of 11 Chi tilts in the range of $-45^{\circ}$ to $45^{\circ}$ along three rotations $\left(0^{\circ}, 45^{\circ}, 90^{\circ}\right)$ were run. The residual stress profile was calculated using the $\sin ^{2}(\psi)$ method (Ref 26). Seven measurements were taken from top surface to interface, by removing each time $0.06 \mathrm{~mm}$ of material through electro-polishing with a solution of $94 \%$ acetic acid $-6 \%$ perchloric acid. Microflat tensile (MFT) testing and residual stress measurement were performed on as-sprayed coatings produced at $500{ }^{\circ} \mathrm{C}-60$ bar and on the same samples after heat treatment at $225^{\circ} \mathrm{C}$.

\section{Results and Discussion}

\section{Feedstock Powder Microstructure}

Figure 1(a) shows the etched optical micrograph of the powder showing irregular morphology of the feedstock powder with a dendritic/cellular-like microstructure. The grain size is mostly homogeneous within a single particle, although it varies between particles of different size. The BSE image in Fig. 1(b) confirms the dendritic structure of the powders, with significant solute segregation at grain boundaries (GBs), evidenced by the sharp contrast due to the higher atomic number.

Figure 2 shows XRD patterns of the initial powder, as well as the cold-sprayed coating and $225^{\circ} \mathrm{C}$ heat-treated coating. In the powder, expected peaks of aluminum and silicon, as well as $\theta-\mathrm{Al}_{2} \mathrm{Cu}$ phases, were detected. Hence, it is likely that $\mathrm{Al}_{2} \mathrm{Cu}$ precipitates are present at grain boundaries, shown in Fig. 1(b), also considering the higher BSE contrast associated with $\mathrm{Cu}$. Such precipitates are expected in similar $\mathrm{Al}$ alloys, along with $\mathrm{Q}-\mathrm{Al}_{5} \mathrm{Cu}_{2} \mathrm{Mg}_{8} \mathrm{Si}_{6}$, and $\beta-\mathrm{Mg}_{2} \mathrm{Si}$ (Ref 19), which may be too small in weight \% to be detected by XRD. Regarding the \% of phases calculated via Rietveld refinement, an error of $\sim 5 \%$ or 

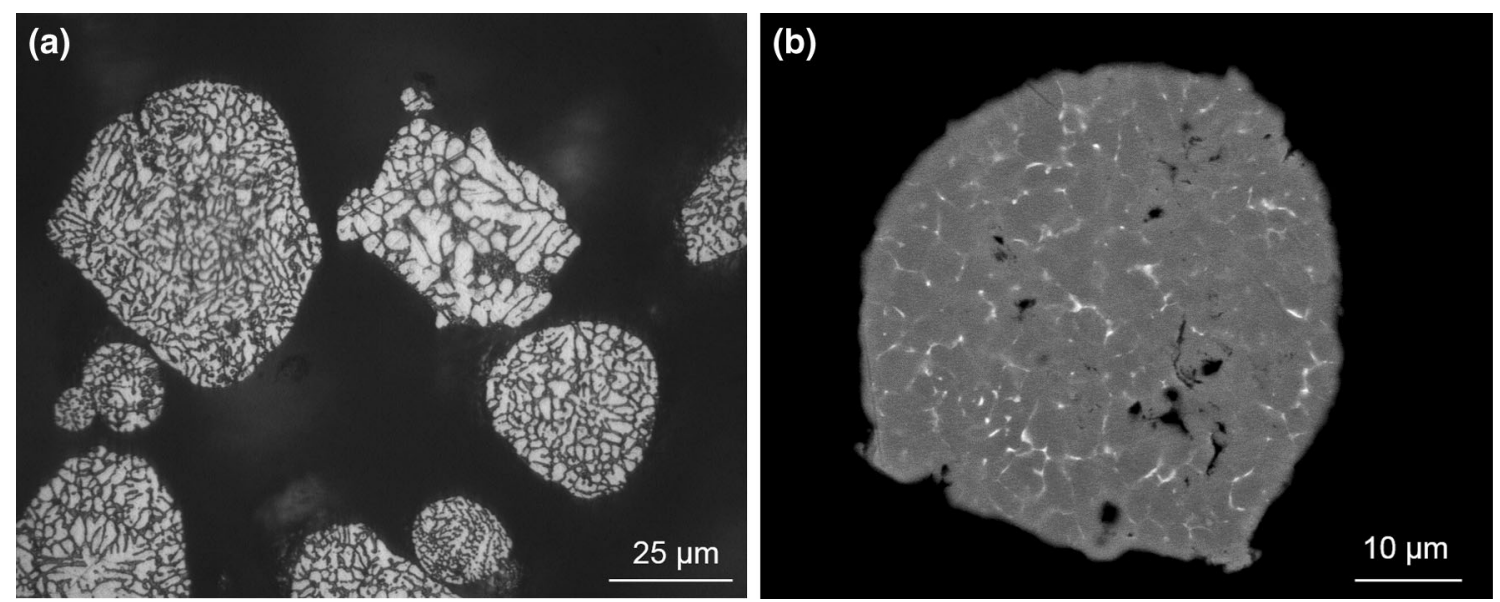

Fig. 1 C355 feedstock powder. (a) Optical micrograph of etched cross section of particles. (b) Backscattered electron (BSE) image of powder cross section

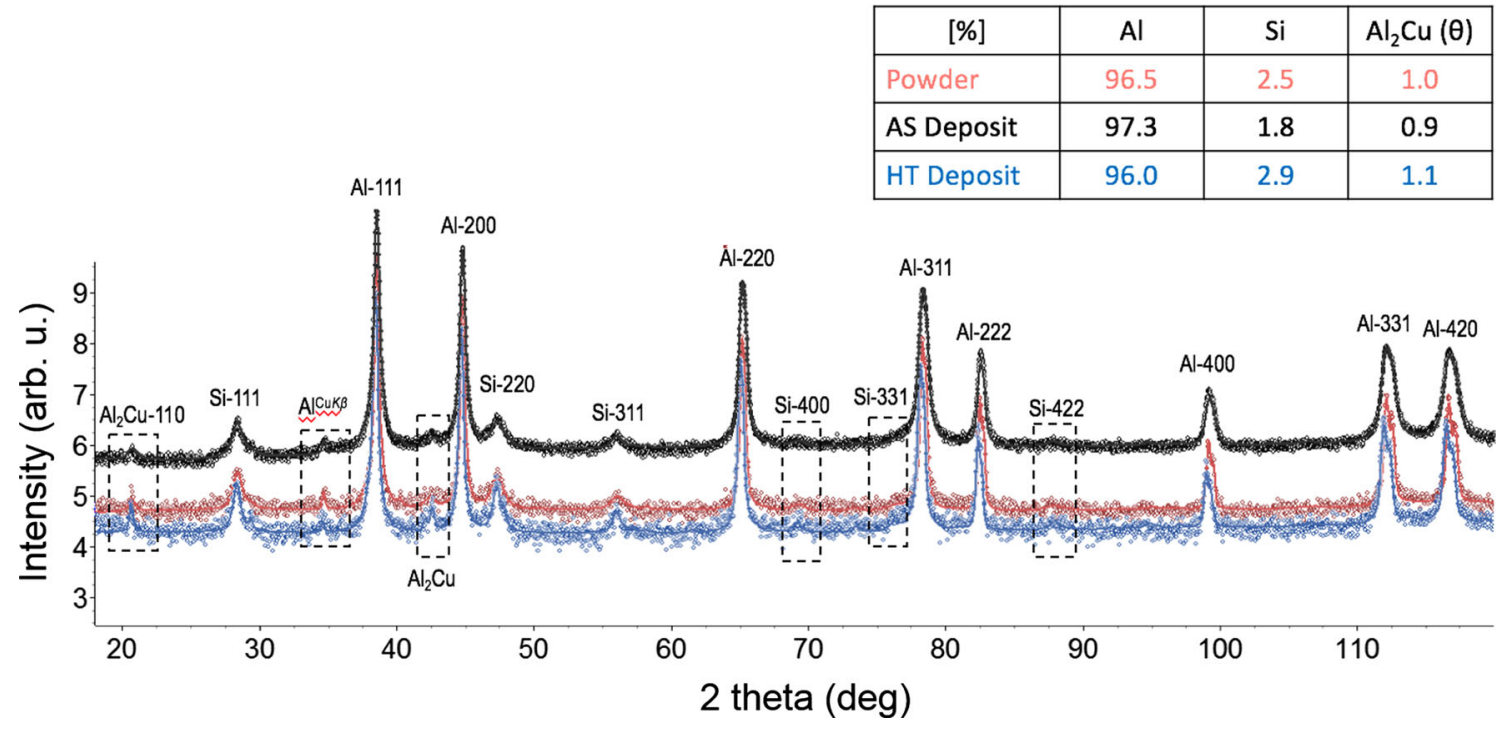

Fig. 2 XRD patterns of powder, as-sprayed and HT-225 ${ }^{\circ} \mathrm{C}$ coatings

higher is often expected by the technique. Torre and Aranda noted that laboratory x-ray Rietveld data yielded relative errors for a cement mixture on the order of $2-3 \%$ for primary phases (above $\sim 10 \%$ by weight) in comparison with original measured weights and 5-10\% for the lowcontent phases (below $\sim 10 \%$ by weight) (Ref 27). It has also been shown that relative errors of $20 \%$ or higher can be expected for phases with weight content below 1\% (Ref 28).

\section{As-Sprayed Coating Microstructure}

Optical micrographs of the as-sprayed coating produced at are shown in Fig. 3. Various parameters were initially trialed, but characterization was performed using samples yielding the lowest porosity—achieved using primary gas temperature of $500{ }^{\circ} \mathrm{C}$, gas pressure of $60 \mathrm{bar}$, and standoff distance of $50 \mathrm{~mm}$. The coating appears as layers of splats typical to cold spray, with extensive particle deformation which is a characteristic of a good coating (see Fig. 3b). This is explained by the high gas temperature and/or pressure allowing for higher particle velocity and temperature which, in turn, result in enhanced particle deformation, small pores, thin inter-splat cracks, and reduced overall level of porosity. The etched microstructure shows severe particle deformation due to solid state particle impact, and there are some particles which did not have a clear dendritic structure which were identified as pure $\mathrm{Al}$ alloy powders in EDX.

In Fig. 3(b), pores at particle boundaries can be seen. These are pores created due to imperfect deformation at the interface of particles. The microstructure seen in 

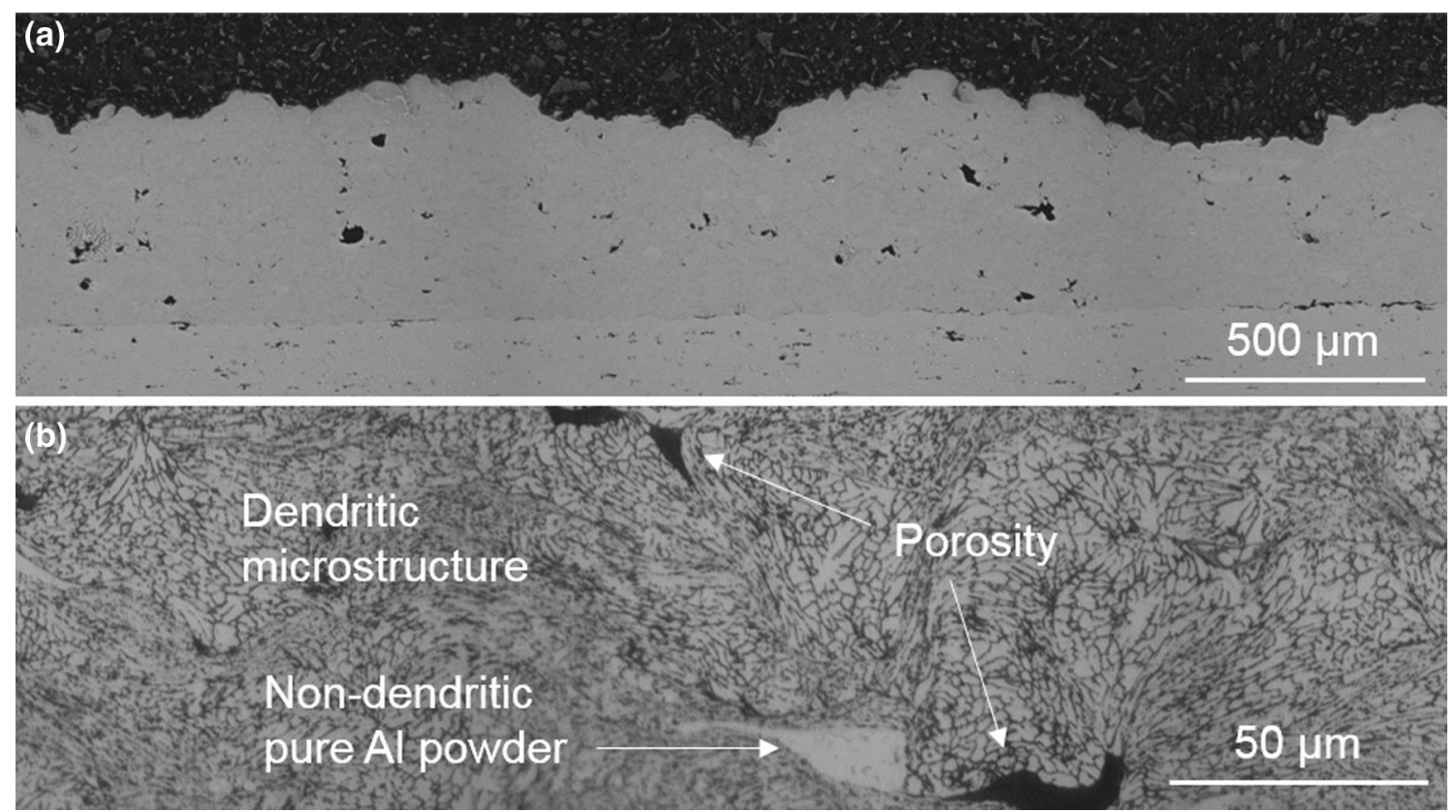

Fig. 3 Optical micrographs of as-sprayed coating produced (a) unetched, and (b) etched revealing general dendritic microstructure, inter-particle porosity, and a non-dendritic pure Al particle

Fig. 3(b) shows the same dendritic features that were found in the feedstock powder (Fig. 1a), although much deformation of the microstructure can be seen. This suggests that, at the macroscale, no significant change has happened to the structure of the particles during deposition from feedstock powder to deposited splats. The XRD pattern of the coating, shown in Fig. 2, confirms that the phases present after deposition are the same $(\mathrm{Al}, \mathrm{Si}, \theta)$ as those in the feedstock powder and no detectable oxidation of the aluminum splats occurred during the spray deposition. Additionally, Rietveld analysis was performed on the XRD patterns, showing that the amount of each phase present is also retained (table in Fig. 2).

\section{Heat-Treated Coating Morphology and Microstructure}

Optical micrographs of heat-treated coatings are shown in Fig. 4. It is clear that the level of porosity in the treated coatings decreased with increasing treatment temperature ranging from 175 to $250{ }^{\circ} \mathrm{C}$, with a reduction of over $40 \%$ for each step increment of $25{ }^{\circ} \mathrm{C}$. Notably, the heat-treated coating at $225^{\circ} \mathrm{C}$ (Fig. 4d) yielded a reduction in porosity of $90 \%$ compared to the as-sprayed state (Fig. 4a). Interparticle gaps between splats also appeared slightly thinner after heat treatment-therefore, likely providing enhanced particle-particle bonding due to diffusion. The light phase appearing in some optical images is thought to be pure $\mathrm{Al}$ powder, a small amount of which was present in the C355 batch.
The decrease in inter-particle porosity after heat treatment is similar to that seen by Huang et al. (Ref 7) in commercially pure $\mathrm{Al}$ and Ti cold-sprayed porous deposits. Huang et al. also noted a correlation between heat treatment temperature and level of reduction in porosity, and explained the process by a simple diffusion mechanism. At $175{ }^{\circ} \mathrm{C}$ (Fig. 4b) and $200{ }^{\circ} \mathrm{C}$ (Fig. 4c), diffusion is low, and its effect becomes more pronounced for sufficiently high temperatures. For treatment temperatures above $225^{\circ} \mathrm{C}$ (Fig. $4 \mathrm{~d}$ and e), some particle boundaries start disappearing and additional chem$\mathrm{ical} /$ metallurgical bonding is created where the interfaces were bonded solely by mechanical interlocking. Also, when the interface of the particles becomes obscured at high treating temperatures $\left(225\right.$ and $\left.250{ }^{\circ} \mathrm{C}\right)$, improvement in the bond strength at the particle interface can be expected. As a result, the adhesive and cohesive bonding is enhanced (Ref 6). However, the temperatures used in this study are not high enough to initiate recrystallization, or to produce any other major modification to the microstructure. In addition to this, the relatively low temperatures employed in this study prevent the complete removal of defects present in the assprayed state.

EPMA analysis was performed on the cross sections of the as-sprayed coating and the $225{ }^{\circ} \mathrm{C}$ heat-treated coating. EPMA results of $\mathrm{Cu}$ in the as-sprayed and heat-treated states are shown in Fig. 5 . $\mathrm{Cu}$ is shown given its low overall wt. $\%$ and its heterogeneity in the as-sprayed form. The as-sprayed distribution of $\mathrm{Cu}$ is consistent with the dendritic structure and $\mathrm{Al}_{2} \mathrm{Cu}$ precipitates in the as-received powder and the as-sprayed coating. It is non- 

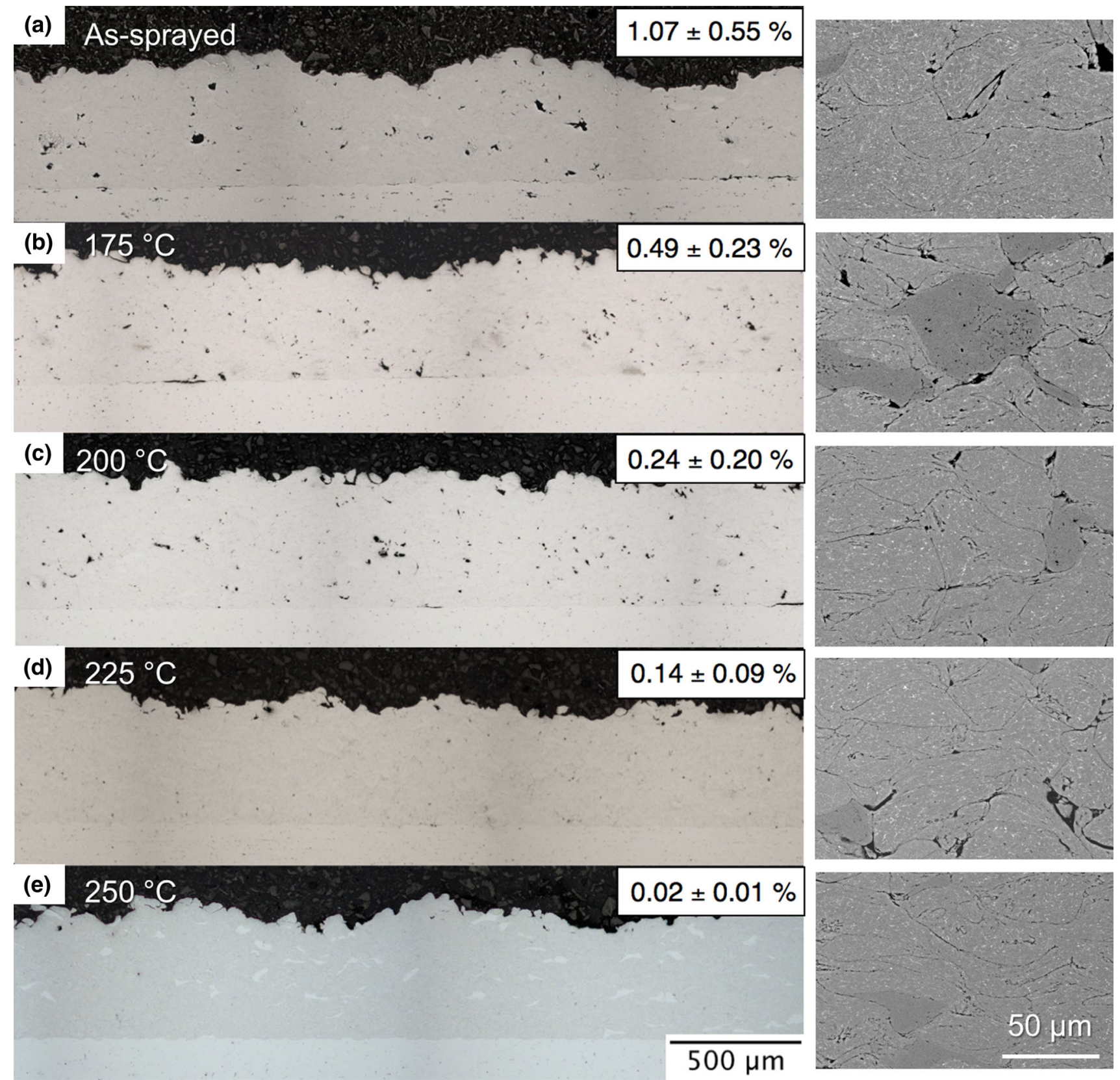

Fig. 4 Coatings (a) as-sprayed, and after heat treatment at (b) $175{ }^{\circ} \mathrm{C}$, (c) $200{ }^{\circ} \mathrm{C}$, (d) $225{ }^{\circ} \mathrm{C}$, and (e) $250{ }^{\circ} \mathrm{C}$ for $4 \mathrm{~h}$ in air. Area porosity $\%$ and error are included in top right. Higher magnification images are shown on the right

uniformly distributed and separated by distances matching those of the grains seen in the optical micrographs which reveal microstructures, such as in Fig. 3(b). In the case of the heat-treated coating, $\mathrm{Cu}$ distribution is more uniform, with higher levels (green on the map as opposed to blue/ black) seen in regions between what are assumed to be precipitates. This is despite the even higher absolute scale for the heat-treated coating. This result is somewhat evident of diffusion which led to a reduction in porosity. In $\mathrm{Al}$, the level of $\mathrm{Cu}$ in solid solution decreases with decreasing temperature to $0.1-0.2 \mathrm{wt} . \%$ at $250{ }^{\circ} \mathrm{C}(\operatorname{Ref} 29)$.
Therefore, despite $225^{\circ} \mathrm{C}$ being at the lower end of the temperature range under which diffusion of $\mathrm{Cu}$ into solid solution can occur, this may still explain the movement of a small level of $\mathrm{Cu}$ from precipitates. Formation of fine intermetallic particles of $\mathrm{Al}_{2} \mathrm{Cu}$ in $\mathrm{C} 355$ alloy from the solid solution during heat treatment between 150 and $220{ }^{\circ} \mathrm{C}$ has also been observed (Ref 30 ), and hence the apparent homogenization of $\mathrm{Cu}$ could also be caused by further small $\mathrm{Al}_{2} \mathrm{Cu}$ particle formation. It should also be noted that the majority of $\mathrm{Cu}$ present is still heterogeneous and remains as precipitates after heat treatment. 
Fig. 5 EPMA analysis showing distribution of $\mathrm{Cu}$ before and after $225^{\circ} \mathrm{C}$ HT

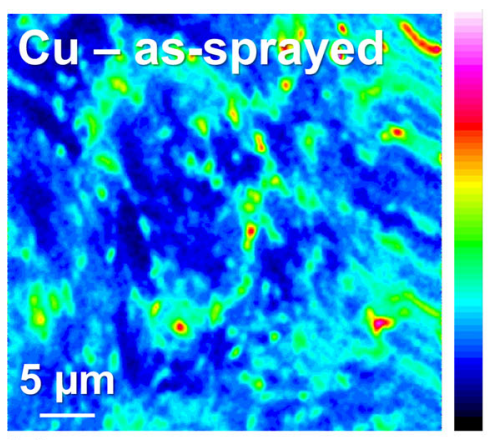

(a)

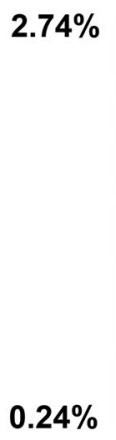

(b)

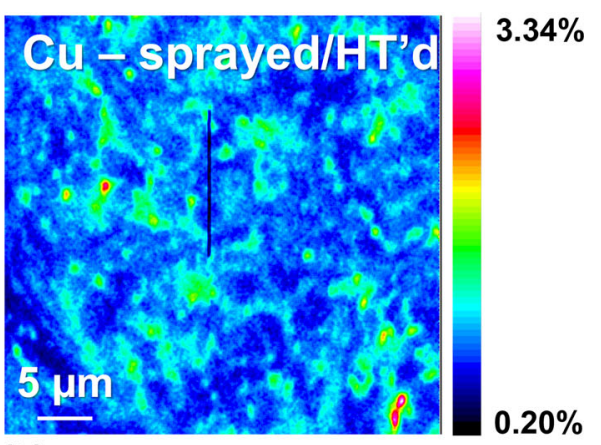

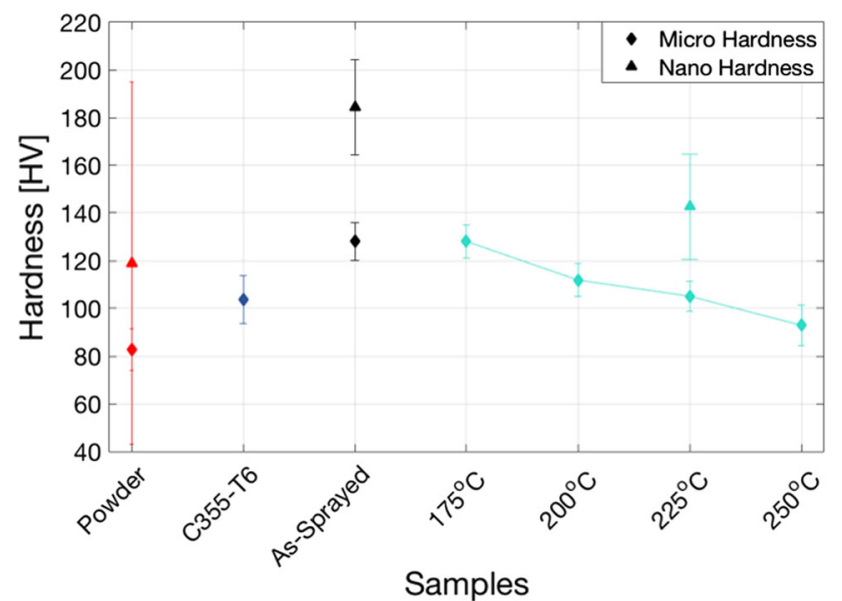

Fig. 6 Vickers microhardness of powder, C355-T6 bulk, as-sprayed and heat-treated coatings. Nanohardness of powder, as-sprayed, and HT-225 ${ }^{\circ} \mathrm{C}$ coatings

\section{Hardness}

Figure 6 shows the results of Vickers microhardness and nanoindentation measurements. As-sprayed coatings yielded a microhardness value of $130 \pm 5 \mathrm{HV}_{0.05}$ and did not present a significant trend along the coating. The microhardness of as-sprayed coatings, as expected, was much higher than that of the feedstock powder $\left(83 \pm 8 \mathrm{HV}_{0.01}\right)$, consistent with other work (Ref 31 ) that reports an increase in microhardness of cold-sprayed coatings by $50 \%$ compared to feedstock powder. The microhardness of assprayed coatings was also $25 \%$ higher than that of C355 Al bulk in its peak-aged (T6) condition (104 $\left.\pm 10 \mathrm{HV}_{0.05}\right)$. Nanohardness measurement results for the original powder, the as-sprayed coating and the $225{ }^{\circ} \mathrm{C}$ heat-treated coating, converted to Vickers hardness number are also shown in Fig. 6. The trend of nanohardness results reflects close the microhardness measurements; however, mean hardness is increased by 40-50 HV for all three samples. The discrepancy between the microhardness and nanoindentation results may be explained by the smaller area over which the nanoindentation took place. Relatively large indents associated with microindentation are more likely to be testing material which contains porosity, which would hence reduce measured hardness. On the other hand, smaller nanoindents are more likely to avoid porous regions on average; however, individual indents which come in contact with such regions would yield a much larger change in measured hardness. Additionally, smaller indentation area would increase chance of contacting precipitates. This would also explain the larger error measured for all nanoindentation results.

The high hardness of the coatings relative to the feedstock powder is attributed to high strain rate plastic deformation that the deposited particles undergo during deposition, which is typical to cold spray. Such high strain rate plastic deformation is characterized by the presence of dislocation loops which have been observed directly via TEM in the case of pure copper and stainless steel (Ref 32, 33). The predominant strengthening mechanism is likely to be work hardening due to an increased dislocation density calculated in the as-sprayed coatings $\left(0.8 \times 10^{15} \mathrm{~m}^{-2}\right)$. The high dislocation density calculated is mainly due to the increased average microstrain (from 0.34 to $0.73 \%$ ) and decreased CDD (from $>200$ to $118 \mathrm{~nm}$ ) from powder to as-sprayed coatings. This latter phenomenon is an indication that grain refinement may also contribute to strengthening, based on the Hall-Petch relationship (Ref 34); however, given the well-characterized formation of dislocation loops after cold spraying (Ref 32 ), grain refinement is unlikely to be the primary contributor. The CDD and the microstrain values were calculated from the XRD whole powder pattern modeling presented in the experimental method.

The effect of post-deposition heat treatment at various temperatures on hardness is shown in Fig. 6. Microhardness decreases with increasing the treatment temperature, from a value comparable to the as-sprayed coatings $\left(128 \pm 7 \mathrm{HV}_{0.05}\right.$ at $\left.175{ }^{\circ} \mathrm{C}\right)$ to $93 \pm 8 \mathrm{HV}_{0.05}$ at $250{ }^{\circ} \mathrm{C}$. Medium temperatures-200, $225^{\circ} \mathrm{C}$-yielded hardness of $112 \pm 7 \mathrm{HV}_{0.05}$ and $105 \pm 6 \mathrm{HV}_{0.05}$, respectively. To summarize, heat treatment at $225^{\circ} \mathrm{C}$ retains some 
hardness, compared to the C355 bulk-T6. The decrease in hardness is explained by the rearrangement and reduction in dislocations due to heat treatment. Dislocation density decreases from $0.8 \times 10^{15}$ to $0.3 \times 10^{15} \mathrm{~m}^{-2}$ after heat treatment at $225{ }^{\circ} \mathrm{C}$. Additionally, the slight dissolution of the precipitates evidenced by the EPMA maps in Fig. 5 may contribute to the reduced nano/microhardness. The trend of reduced hardness with increasing heat treatment temperature is supported by other work on cold-sprayed coatings as well. Coddet et al. (Ref 35) measured a linearly decreasing hardness property for their cold-sprayed copperbased alloy, explained by dissolution of precipitates by heat treatment. Similarly, Rokni et al. (Ref 11) measured reduced hardness in $412{ }^{\circ} \mathrm{C}$ heat treatment on 7075 coldsprayed $\mathrm{Al}$ alloy, explained by grain growth which was not seen in the current work.

\section{Tensile Properties}

The results of the microflat tensile testing are presented in Fig. 7. As-sprayed deposits showed highly brittle behavior, without any evidence of necking prior to failure. In the assprayed state, ultimate tensile strength, Young's modulus, and elongation were $199 \mathrm{MPa}, 33.9 \mathrm{GPa}$, and $0.67 \%$, respectively. The failure mode was primarily de-cohesive, taking place at the interface between particles prior to undergoing any significant plastic deformation. This result is likely explained by the presence of defects within the deposit, i.e., porosity and microcracks, which are known to strongly influence the mechanical properties (Ref 1), such that their negative impact outweighs the strengthening benefit associated with cold working and dislocation density increase.

The heat-treated $-225{ }^{\circ} \mathrm{C}$ deposit showed improved behavior compared to the as-sprayed state, in terms of both UTS (230 MPa) and elongation (0.97\%). Heat-treated coatings also showed higher yield strength compared to C355 bulk-T6 (228 MPa versus $172 \mathrm{MPa}$ ) (Ref 36). Below the elastic limit, the behavior is similar, as both as-sprayed

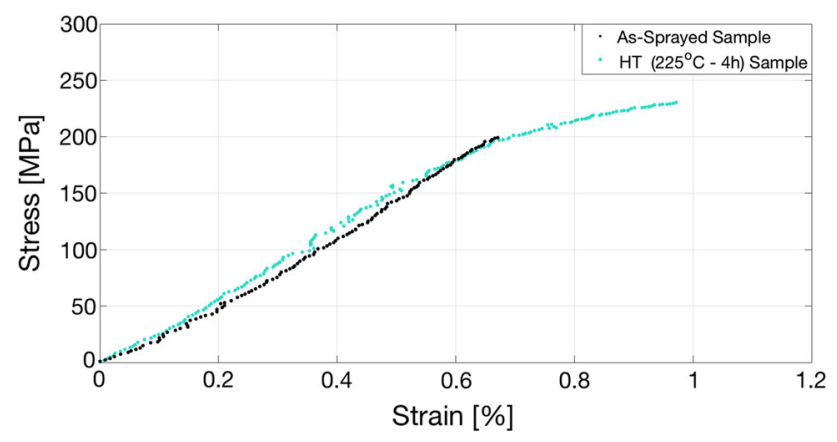

Fig. 7 Results of microflat tensile test of as-sprayed and heat-treated $\left(225{ }^{\circ} \mathrm{C}\right)$ deposits and heat-treated samples yielded comparable values of Young's modulus (Fig. 7). The improvement in tensile properties can be explained by: (1) improved chemical/ metallurgical bonding due to diffusion during heat treatment (2) decreased level of porosity and defects which enhance particle cohesion, and (3) partial relief of the work-hardened states. The first two factors lead to higher UTS, while the third is more likely responsible for improved ductility and reduced brittle behavior at rupture. Rokni et al. (Ref 7) also explained similarly improved UTS and ductility in heat-treated 7075 cold-sprayed deposits via atomic diffusion and microstructural sintering at prior particle boundaries, evidence for both of which was seen here.

\section{Residual Stress}

Figure 8 shows the residual stress profiles as a function of depth into the as-sprayed and $225{ }^{\circ} \mathrm{C}$ heat-treated coatings. In the as-sprayed state, the stress is compressive (negative) through the entire thickness, being slightly reduced at the very top surface. This relaxation is due to the reduced tamping effect experienced by the last deposited layers. On the other hand, the increased stress approaching the interface between coating and substrate is evidence of the peening effect induced on both the low layers of the coating as well as the substrate by the cold-spraying process.

After heat treatment at $225{ }^{\circ} \mathrm{C}$, the stress state is still compressive, but decreased by half in magnitude at all depths into the coating, including on the surface. This finding agrees with halving of the microstrains discussed in "Hardness" section. Although the presence of compressive

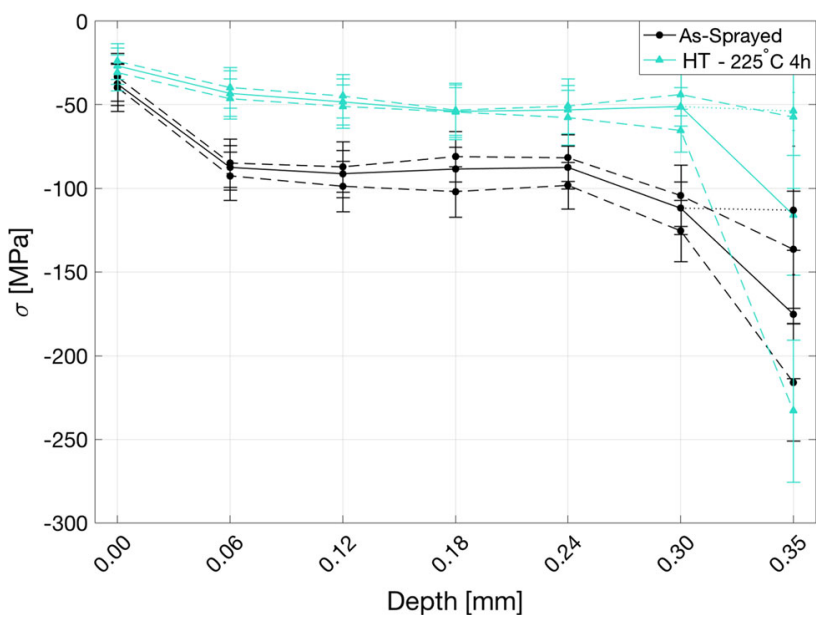

Fig. 8 Residual stress profile along the thickness of as-sprayed and heat-treated $-225{ }^{\circ} \mathrm{C}$ coatings. The solid lines represent the average along three rotations $\left(0^{\circ}, 45^{\circ}, 90^{\circ}\right)$, and the dashed lines are the maximum and minimum principal stresses 
residual stress can potentially be beneficial for example to fatigue life, the partial release of residual stress after heat treatment is useful as excessive compressive residual stress can cause adhesive and/or cohesive failure of coatings. The highest compressive residual stress being nearest the coating/substrate interface has been observed in other work (Ref 12). Suhonen et al. (Ref 17) observed that surface preparation and substrate type strongly influence type and level of residual stress in the first layer of the coating during cold spray, and in particular $\mathrm{Al}$ substrates tended to promote higher compressive residual stresses in comparison with other substrates of carbon steel and stainless steel, although an explanation for this was not presented. Despite this, the high residual stress near the substrate/coating interface, i.e., beyond $0.35 \mathrm{~mm}$ depth, may be explained via the influence of substrate material as well as the peening effect during spraying.

\section{Conclusions}

Aluminum alloy C355 deposits were produced using a cold spray system onto 6082 aluminum substrates. Optimal spray parameters were selected upon microstructural and mechanical investigation of the coatings. Heat treatment at a range of temperatures: $175,200,225,250{ }^{\circ} \mathrm{C}$ was performed, and the most promising condition that enhanced both microstructural and mechanical properties was identified and reported here. The main findings of the study are:

- Cold spraying at a temperature of $500{ }^{\circ} \mathrm{C}$ and pressure of 60 bar yielded a coating with porosity level of $\sim 1 \%$, a microhardness of $130 \pm 5 \mathrm{HV}_{0.05}$. A compressive residual stress state through the coating thickness was also measured by XRD, highest in magnitude near to the coating-substrate interface.

- Heat treatment of $\mathrm{Al} \mathrm{C355}$ coatings reduced porosity due to a diffusion mechanism (to $0.02 \%$ ), being more effective with increasing treatment temperature. Diffusion of minor elements was also evidenced by EPMA analysis. The best combination of reduced porosity and microhardness retention was obtained for heat treatment temperature of $225{ }^{\circ} \mathrm{C}$, i.e., $0.14 \%$ porosity, $105 \pm 6 \mathrm{HV}_{0.05}$.

- Heat treatment at $225{ }^{\circ} \mathrm{C}$ yielded a slightly increased ultimate tensile strength and an improvement in ductility. Compressive residual stress values were approximately halved after heat treatment for all depth levels into the coatings. This is potentially beneficial in preventing cohesive/adhesive failure.

Acknowledgments This work was supported by the Engineering and Physical Sciences Research Council [grant number EP/M50810X/1].
The authors also acknowledge support from The Welding Institute (TWI), UK and Politecnico di Milano, Italy.

Open Access This article is distributed under the terms of the Creative Commons Attribution 4.0 International License (http://crea tivecommons.org/licenses/by/4.0/), which permits unrestricted use, distribution, and reproduction in any medium, provided you give appropriate credit to the original author(s) and the source, provide a link to the Creative Commons license, and indicate if changes were made.

\section{References}

1. E. Irissou, J.-G. Legoux, B. Arsenault, and C. Moreau, Investigation of $\mathrm{Al}-\mathrm{Al}_{2} \mathrm{O}_{3}$ Cold Spray Coating Formation and Properties, J. Therm. Spray Technol., 2007, 16(5), p 661-668

2. A. Papyrin, Cold Spray Technology, Adv. Mater. Process., 2001, 159(9), p 49-51

3. R. Morgan, P. Fox, J. Pattison, C. Sutcliffe, and W. O'Neill, Analysis of Cold Gas Dynamically Sprayed Aluminium Deposits, Mater. Lett., 2004, 58(7-8), p 1317-1320

4. R.C. McCune, W.T. Donlon, O.O. Popoola, and E.L. Cartwright, Characterization of Copper Layers Produced by Cold Gas-Dynamic Spraying, J. Therm. Spray Technol., 2000, 9(1), p 73-82

5. R.S. Lima, A. Kucuk, C.C. Berndt, J. Karthikeyan, C.M. Kay, and J. Lindemann, Deposition Efficiency, Mechanical Properties and Coating Roughness in Cold-Sprayed Titanium, J. Mater. Sci. Lett., 2002, 21(21), p 1687-1689

6. C. Lee and J. Kim, Microstructure of Kinetic Spray Coatings: A Review, J. Therm. Spray Technol., 2015, 24(4), p 592-610

7. R. Huang, M. Sone, W. Ma, and H. Fukanuma, The Effects of Heat Treatment on the Mechanical Properties of Cold-Sprayed Coatings, Surf. Coat. Technol., 2015, 261, p 278-288

8. E. Sansoucy, G.E. Kim, A.L. Moran, and B. Jodoin, Mechanical Characteristics of Al-Co-Ce Coatings Produced by the Cold Spray Process, J. Therm. Spray Technol., 2007, 16(5), p 651-660

9. C.Y. Jeong and S. Ha, Fatigue Properties of Al-Si Casting Alloy with Cold Sprayed Al/SiC Coating, Int. J. Cast Met. Res., 2008, 21(1-4), p 235-238

10. W.-Y. Li, C.-J. Li, and H. Liao, Effect of Annealing Treatment on the Microstructure and Properties of Cold-Sprayed Cu Coating, $J$. Therm. Spray Technol., 2006, 15(2), p 206-211

11. M.R. Rokni, C.A. Widener, V.K. Champagne, G.A. Crawford, and S.R. Nutt, The Effects of Heat Treatment on 7075 Al Cold Spray Deposits, Surf. Coat. Technol., 2017, 310, p 278-285

12. M.R. Rokni, C.A. Widener, O.C. Ozdemir, and G.A. Crawford, Microstructure and Mechanical Properties of Cold Sprayed 6061 Al in As-Sprayed and Heat Treated Condition, Surf. Coat. Technol., 2017, 309, p 641-650

13. A.C. Hall, D.J. Cook, R.A. Neiser, T.J. Roemer, and D.A. Hirschfeld, The Effect of a Simple Annealing Heat Treatment on the Mechanical Properties of Cold-Sprayed Aluminum, J. Therm. Spray Technol., 2006, 15(2), p 233-238

14. A. Moridi, S.M.H. Gangaraj, S. Vezzu, and M. Guagliano, Number of Passes and Thickness Effect on Mechanical Characteristics of Cold Spray Coating, Procedia Eng., 2014, 74(Supplement C), p 449-459

15. Z. Arabgol, H. Assadi, T. Schmidt, F. Gärtner, and T. Klassen, Analysis of Thermal History and Residual Stress in Cold-Sprayed Coatings, J. Therm. Spray Technol., 2014, 23(1), p 84-90

16. G. Shayegan, H. Mahmoudi, R. Ghelichi, J. Villafuerte, J. Wang, M. Guagliano, and H. Jahed, Residual Stress Induced by Cold Spray Coating of Magnesium AZ31B Extrusion, Mater. Des., 2014, 60(Supplement C), p 72-84 
17. T. Suhonen, T. Varis, S. Dosta, M. Torrell, and J.M. Guilemany, Residual Stress Development in Cold Sprayed $\mathrm{Al}, \mathrm{Cu}$ and $\mathrm{Ti}$ Coatings, Acta Mater., 2013, 61(17), p 6329-6337

18. N.B. Maledi, O.P. Oladijo, I. Botef, T.P. Ntsoane, A. Madiseng, and L. Moloisane, Influence of Cold Spray Parameters on the Microstructures and Residual Stress of $\mathrm{Zn}$ Coatings Sprayed on Mild Steel, Surf. Coat. Technol., 2017, 318, p 106-113

19. G. Mrowka-Nowotnik and J. Sieniawski, Microstructure and Mechanical Properties of C355.0 Cast Aluminium Alloy, Arch. Mater. Sci. Eng., 2011, 47(2), p 85-94

20. H.E. Chandler and Knovel, Heat Treater's Guide [Electronic Resource]: Practices and Procedures for Nonferrous Alloys, $\mathrm{H}$. Chandler, Ed., ASM International, Materials Park, 1996

21. H. Rietveld, Line Profiles of Neutron Powder-Diffraction Peaks for Structure Refinement, Acta Crystallogr. A, 1967, 22(1), p 151152

22. P. Scardi and M. Leoni, Whole Powder Pattern Modelling, Acta Crystallogr. A, 2002, 58(2), p 190-200

23. M.R. Rokni, C.A. Widener, V.K. Champagne, and G.A. Crawford, Microstructure and Mechanical Properties of Cold Sprayed 7075 Deposition During Non-isothermal Annealing, Surf. Coat. Technol., 2015, 276, p 305-315

24. A. Ilzhöfer, H. Schneider, and C. Tsakmakis, Tensile Testing Device for Microstructured Specimens, Microsyst. Technol., 1997, 4(1), p 46-50

25. M. Guagliano, L'applicazione della diffrattometria dei raggi $X$ per l'analisi del cedimento dei componenti meccanici, Frattura ed Integrità Strutturale, 2007, 2, p 25-35

26. M.E. Fitzpatrick, A.T. Fry, P. Holdway, F.A. Kandil, J. Shackleton, and L. Suominen, Measurement Good Practice Guide No. 52, Determination of Residual Stresses by X-ray Diffraction Issue 2, National Physical Laboratory report, 2005, ISSN 1744-3911

27. A.G. De la Torre and M.A.G. Aranda, Accuracy in Rietveld Quantitative Phase Analysis of Portland Cements, J. Appl. Crystallogr., 2003, 36(5), p 1169-1176
28. L. León-Reina, M. García-Maté, G. Álvarez-Pinazo, I. Santacruz, O. Vallcorba, A.G. De la Torre, and M.A.G. Aranda, Accuracy in Rietveld Quantitative Phase Analysis: A Comparative Study of Strictly Monochromatic Mo and Cu Radiations, J. Appl. Crystallogr., 2016, 49(Pt 3), p 722-735

29. Z. Li, A.M. Samuel, F.H. Samuel, C. Ravindran, and S. Valtierra, Effect of Alloying Elements on the Segregation and Dissolution of $\mathrm{CuAl}_{2}$ Phase in Al-Si-Cu 319 Alloys, J. Mater. Sci., 2003, 38(6), p 1203-1218

30. G. Mrówka-Nowotnik and J. Sieniawski, Microstructure and Mechanical Properties of C355.0 Cast Aluminium Alloy, Arch. Mater. Sci. Eng., 2011, 47(2), p 85-94

31. S. Rech, A. Trentin, S. Vezzù, J.-G. Legoux, E. Irissou, and M. Guagliano, Influence of Pre-heated Al 6061 Substrate Temperature on the Residual Stresses of Multipass Al Coatings Deposited by Cold Spray, J. Therm. Spray Technol., 2011, 20(1), p 243-251

32. C. Borchers, F. Gärtner, T. Stoltenhoff, and H. Kreye, Formation of Persistent Dislocation Loops by Ultra-High Strain-Rate Deformation During Cold Spraying, Acta Mater., 2005, 53(10), p 2991-3000

33. C. Borchers, T. Schmidt, F. Gärtner, and H. Kreye, High Strain Rate Deformation Microstructures of Stainless Steel 316L by Cold Spraying and Explosive Powder Compaction, Appl. Phys. A, 2008, 90(3), p 517-526

34. K. Ma, H. Wen, T. Hu, T.D. Topping, D. Isheim, D.N. Seidman, E.J. Lavernia, and J.M. Schoenung, Mechanical Behavior and Strengthening Mechanisms in Ultrafine Grain PrecipitationStrengthened Aluminum Alloy, Acta Mater., 2014, 62, p 141155

35. P. Coddet, C. Verdy, C. Coddet, and F. Debray, Effect of Cold Work, Second Phase Precipitation and Heat Treatments on the Mechanical Properties of Copper-Silver Alloys Manufactured by Cold Spray, Mater. Sci. Eng. A, 2015, 637, p 40-47

36. A.I.H. Committee, Properties and Selection: Nonferrous Alloys and Special-Purpose Materials, ASM International, Materials Park, 1990 